\title{
Levels of polyunsaturated fatty acids in lymphocytes of rats fed on diets varying in polyunsaturated fatty acid content
}

\author{
BY W. M. TSANG, J. BELIN AND A. D. SMITH \\ The Courtauld Institute of Biochemistry, The Middlesex \\ Hospital Medical School, Mortimer Street, London, $W_{\mathrm{I}} P{ }_{7} P N$
}

(Received I4 August I979-Accepted I4 November 1979)

\begin{abstract}
I. When weanling rats were fed on a diet containing $0.1 \mathrm{~g} / \mathrm{kg}$ of the diet as polyunsaturated fatty acid, it was found that after 2 weeks the level of linoleate in the lymphocyte total lipids was $56 \mathrm{mg} / \mathrm{g}$ total fatty acids, as compared with a level of $138 \mathrm{mg} / \mathrm{g}$ in rats on a normal diet $(P<0.005)$. Similar levels were obtained from rats which had been fed for up to 16 weeks on the deficient diet, but in a group killed after 28 weeks on the diet the level was found to be only $20 \mathrm{mg} / \mathrm{g}$ total fatty acids. The arachidonate level was found to be approximately $220 \mathrm{mg} / \mathrm{g}$ total fatty acids, regardless of whether the rats were fed on a diet deficient in linoleate for up to 16 weeks or on a normal diet. In the group of rats killed after 28 weeks on the linoleate deficient diet, however, the arachidonate level was only $60 \mathrm{mg} / \mathrm{g}$ total fatty acids.

2. Percentage values for total fatty acids are given for plasma, adipose tissue, and lymphocytes for rats on normal and experimental diets.

3. Scatter diagrams of the levels of linoleate $v$. arachidonate in the lymphocyte total fatty acids showed no correlation between the levels of the two acids $(r 0.05)$, but similar plots of linoleate and oleate levels showed an inverse correlation $(r-0.68)$.
\end{abstract}

A number of reports indicate that both the quantity and the nature of dietary lipid may affect the immune response in mammals. For example, deprivation of essential fatty acids accelerates the rejection of skin grafts in mice (Medawar et al. 1976; Mertin \& Hunt 1976) and enhances the severity of experimental allergic encephalomyelitis in rats (Clausen \& Møller, 1967; Selivonchick \& Johnston, 1975). Supplementation of the diet by polyunsaturated fatty acids to nutritionally-adequate animals prolongs skin-graft survival (SantiagoDelpin \& Szepsenwol, I977) and oral administration of these acids to rats ameliorates the severity of experimental allergic encephalomyelitis (Mertin \& Stackpoole, 1979).

There is also evidence from in vitro experiments that manipulation of the lymphocyte fatty acid patterns can inhibit lymphocyte transformation (Mertin \& Hughes, 1975; Offner \& Clausen, 1975; Tsang et al. 1977; Weyman et al. 1977). It has been suggested that a number of these effects could result from changes in the availability of polyunsaturated fatty acids as precursors for prostaglandin synthesis (Mertin \& Stackpoole, 1979). There is considerable interest in the effect of essential fatty acid (EFA) deficiency on fatty acid patterns of rat tissues (for review, see Guanieri \& Johnson, 1970). However, although changes in fatty acid patterns have been reported for polymorphonuclear leucocytes ( $\mathrm{Yu}$ et al. 1966) there is no information in the literature concerning lymphocytes. We have therefore analysed the lymphocyte total lipid fatty acid patterns in animals maintained on diets of varying linoleate content.

\section{MATERIALS AND METHODS}

Four diets were used, the normal rat diet $(\mathrm{N})$ and three experimental diets, all of which contained fat but which varied in their linoleate content. The experimental diets are designated DL (deficient in linoleate), HL (with high linoleate content) and IL (with intermediate level of linoleate).

The details of the diets are listed in Table I. Diet $\mathrm{N}$ was a normal rat cake diet obtained 
Table I. Composition $(\mathrm{g} / \mathrm{kg})$ of experimental diets

Ingredients:
Sunflower-seed oil
Edible skim milk
Hydrogenated coconut oil
Cholesterol
Crude oil
Meat and bone meal, yeast, fish meal
Vitamin, salt
Wheat, barley,
Maizeflour
Fatty acids:
Lauric acid
Myristic acid
Palmitic acid
Palmitoleic acid
Stearic acid
Oleic acid
Linoleic acid
Arachidonic acid

\begin{tabular}{rrrr}
\multicolumn{4}{c}{ Diet } \\
DL & IL & HL & N \\
- & 20 & 100 & - \\
200 & 200 & 200 & - \\
100 & 80 & - & - \\
10 & 10 & 10 & - \\
- & - & - & 35 \\
- & - & - & 175 \\
100 & 100 & 100 & 30 \\
- & - & - & 760 \\
590 & 590 & 590 & - \\
& & & \\
66.6 & 49.8 & - & - \\
8.9 & 14.6 & - & - \\
5.5 & 9.0 & 6.8 & 15.6 \\
0.4 & 1.0 & 0.4 & 0.9 \\
5.1 & 5.9 & 3.3 & 4.3 \\
1.8 & 3.4 & 14.5 & 13.5 \\
0.1 & 6.4 & 60.3 & 20.3 \\
- & - & - & 2.9
\end{tabular}

from North Eastern Farmers Ltd, Bannermill, Aberdeen, AB9 2QT, Scotland. The dams were maintained on the specified diet from time of mating, the weaners were fed ad lib. from the time of weaning, and their weight was recorded.

Spleen lymphocytes were prepared by the method of Bøyum (I968), by teasing the spleen with forceps and layering the cell suspension over lymphoprep (Nyegaard, Oslo). The cells were collected at the interphase and washed three times with medium RPMI 640 (GIBCO, Paisley, PA3 4 EP, Scotland). Extractions were carried out according to Folch et al. (I956) using chloroform-methanol $(2: \mathrm{I}, \mathrm{v} / \mathrm{v})$. Plasma $(0.2 \mathrm{ml})$, $100 \mathrm{mg}$ adipose tissue and $50 \times 10^{6}$ lymphocytes in $0.5 \mathrm{ml}$ medium were used for extraction. The lipid extract was washed with 0 - I M-potassium chloride solution. It was evaporated to dryness under nitrogen (oxygen-free), and saponified at $80^{\circ}$ for $\mathrm{I} \mathrm{h}$ in $5 \mathrm{ml}$ ethanolic potassium hydroxide solution. The fatty acids from the acid phase were extracted with redistilled hexane, methylated with diazomethane and applied to a $200 \mathrm{~g}$ diethylene glycol succinate $/ \mathrm{kg}$ chromosorb WHMDS column of a Perkin Elmer FII gas-liquid chromatograph.

\section{RESULTS}

The fatty acid compositions of lymphocyte total lipids from young rats maintained on a diet very low in essential fatty acids, and those for rats on a normal diet are shown in Table 2. In the animals which were fed on the normal diet the level of linoleate in the lymphocyte was $138 \mathrm{mg} / \mathrm{g}$ total fatty acids, whereas in the animals on the essential fatty acid-deficient diet the level of linoleate at a similar time was $56 \mathrm{mg} / \mathrm{g}$, a significantly lower level $(P<0.005)$. In the animals on the essential fatty acid-deficient diet the level was found to be between 43 and 56 $\mathrm{mg} / \mathrm{g}$ until at least the I6th week on this diet. During this period the animal was presumed to be utilizing linoleate stored in adipose and other tissues. However the arachidonate level in the lymphocyte was found to be similar in the animals on the normal and essential fatty acid-deficient diets $(P>0.6)$, despite the fact that, in the plasma, the arachidonate level was lower in the animals fed on the essential fatty acid-deficient diet (after 5 weeks on the diet this difference was highly significant $P<0.001$ ), Table 3 . Confirmation that these changes 


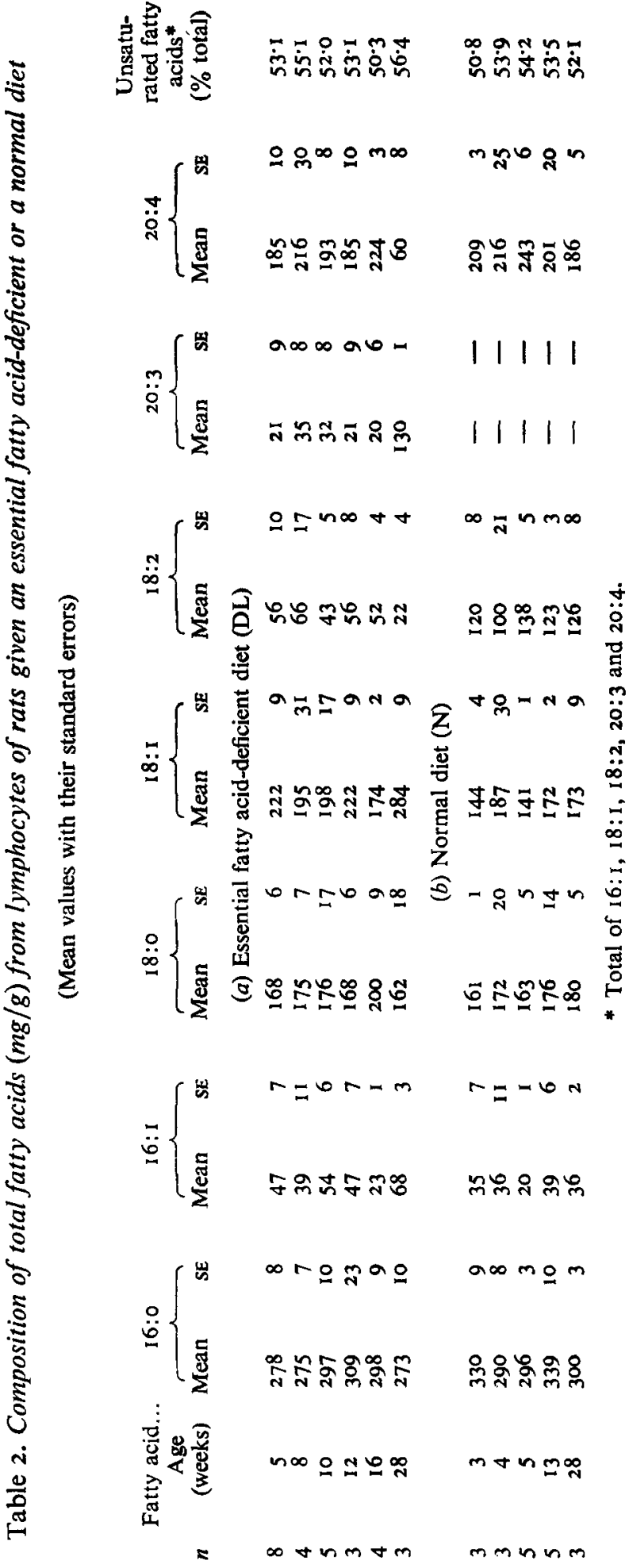




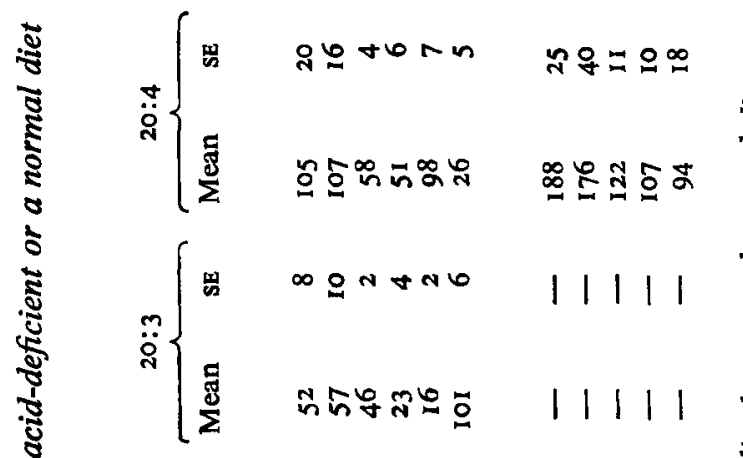

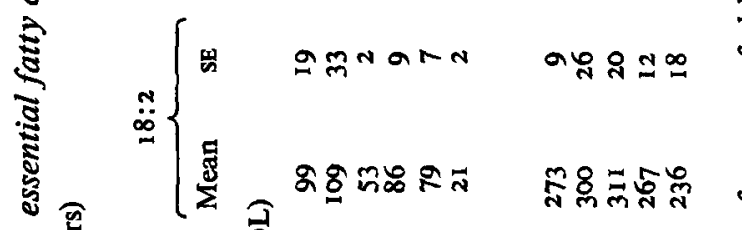

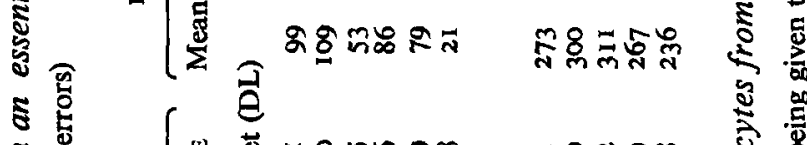

5 岛

ธิ

5 늘

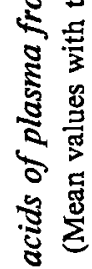

$\frac{2}{5}$

b

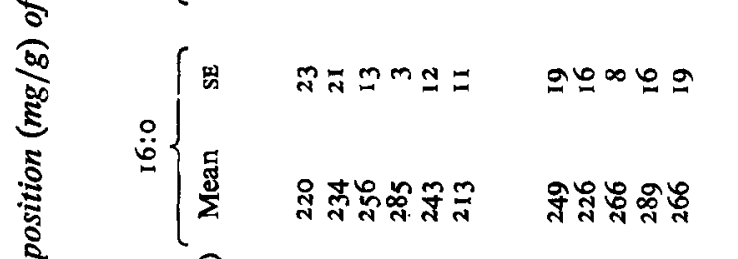

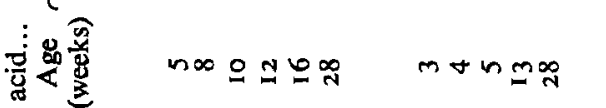

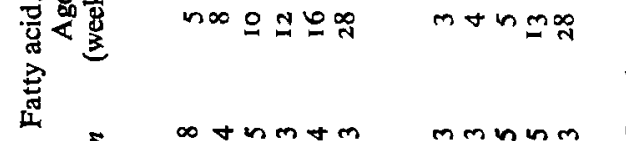

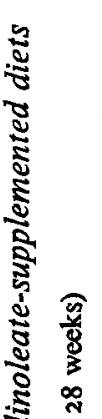

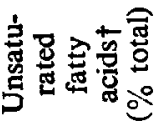

iñ

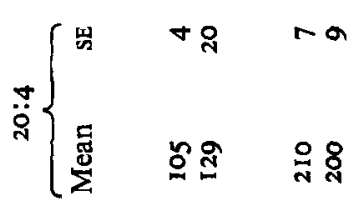

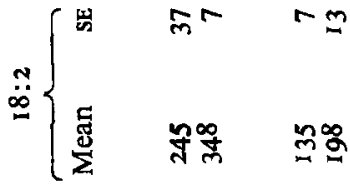

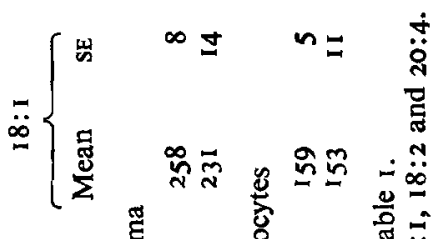

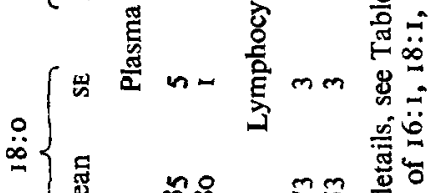

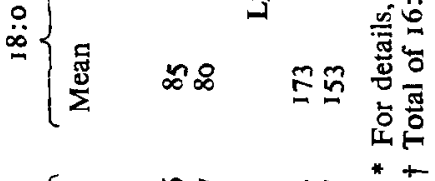

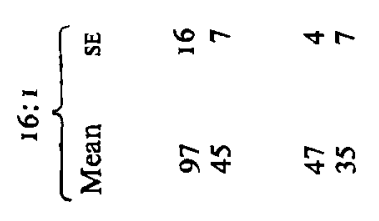

कo

窇

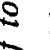

志

$\stackrel{\bullet}{\dot{\theta}}\left\{\begin{array}{lll}g & \text { an } & \text { mo }\end{array}\right.$

토융

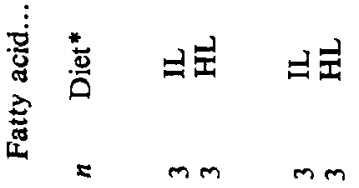




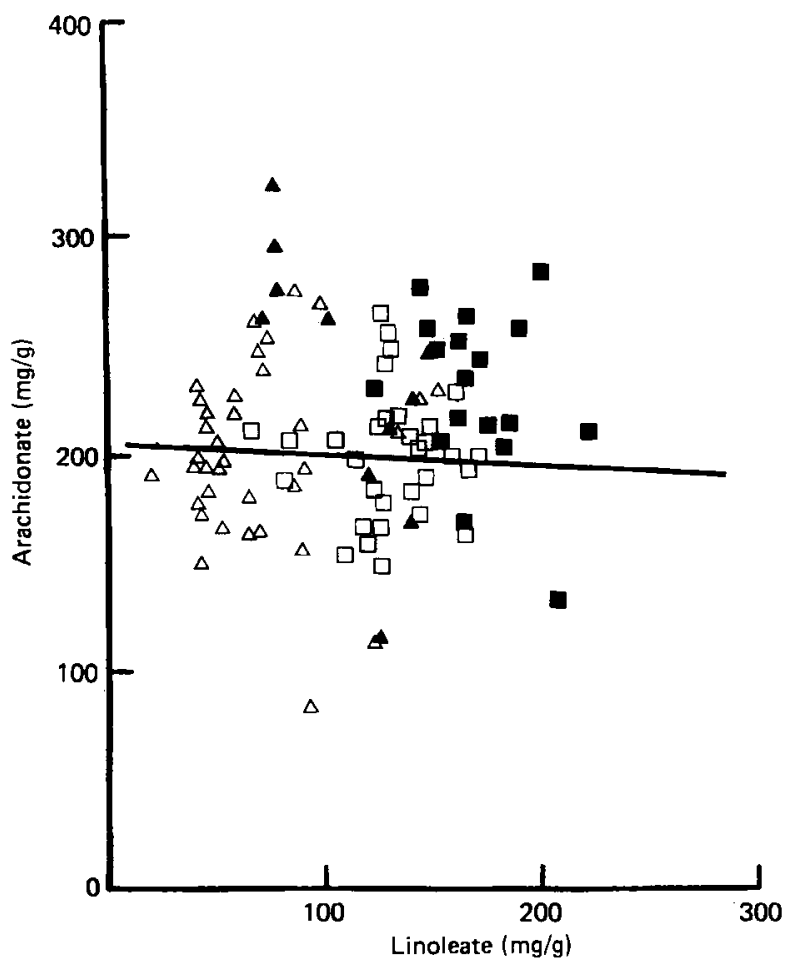

Fig. I. Comparison between arachidonate and linoleate levels (mg/g total fatty acids) in lymphocyte total fatty acids from rats on different diets. Animals killed at 28 weeks were excluded as the effects of extreme essential fatty acid-deficiency were then causing exceptionally large changes in the content of linoleate and arachidonate. Each point represents one animal. $\triangle$, rats fed on an essential fatty acid-deficient diet; $\Delta$, rats fed on a diet containing $20 \mathrm{~g}$ sunflower-seed oil $/ \mathrm{kg}$; $\boldsymbol{B}$, rats fed on a diet containing $100 \mathrm{~g}$ sunflower-seed oil $/ \mathrm{kg} ;[]$, rats fed on a normal rat cake diet; for details of diets, see Table 1 .

were due to the lipid content of the diet is given by comparing the results in Tables 2 and 4 . These show that an experimental diet adequate in linoleate (IL) gave lymphocyte fatty acid patterns comparable to the normal diet at 28 weeks.

When a scatter diagram of the results from individual animals was plotted for linoleate $v$, arachidonate (Fig. I), it was found that there was no correlation between the levels of these acids in the large number of animals studied, confirming that linoleate levels can fluctuate with changes in dietary linoleate without appreciably affecting the level of arachidonate.

A scatter diagram of the linoleate $v$. oleate values (Fig. 2) did, however, reveal an inverse correlation between these two acids $(r-0.68)$, despite the considerable variation from individual to individual. The inverse correlation emerged well from comparison of the levels of these two acids from results in Table 2. It is not so apparent in the results from the two groups of animals reported in Table 4 (animals on diets IL and HL), where the mean linoleate was significantly different $(P<0.005)$ between the two groups whilst the mean oleate was the same in the two groups. This could be because individual variation was sufficiently great that with small groups of animals such as those in Table 4 the correlation was masked by the variation. Additionally, however, it could be that the inverse correlation emerged more clearly as the linoleate level fell below normal, and that, as the linoleate level rose above a certain point, compensation was achieved at the expense of fatty acids other than oleate. 


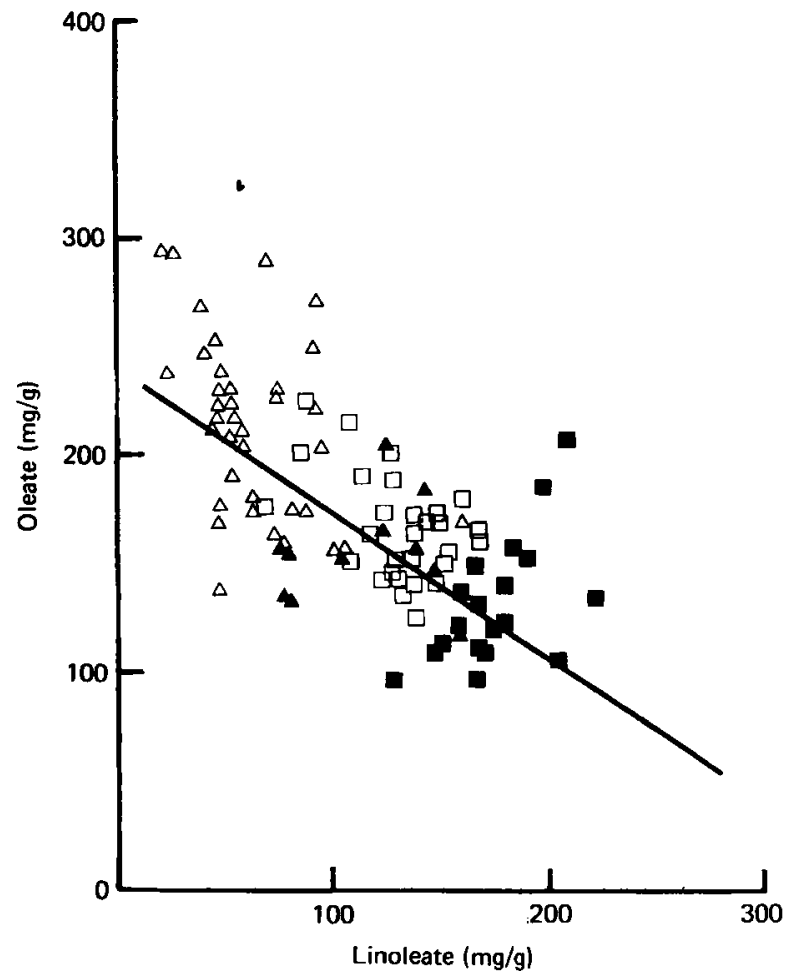

Fig. 2. Comparison between oleate and linoleate levels $(\mathrm{mg} / \mathrm{g}$ total fatty acids) in lymphocyte total fatty acids from rats fed on different diets. $\triangle$, rats fed on an essential fatty acid-deficient diet; $\Delta$, rats fed on a diet containing $20 \mathrm{~g}$ sunflower-seed oil $/ \mathrm{kg}$; $\square$, rats fed on a diet containing $100 \mathrm{~g}$ sunflower-seed oil $/ \mathbf{k g}$; $\square$, rats fed on a normal rat cake diet; for details of diets, see Table $\mathbf{I}$.

Table 5. Composition $(\mathrm{mg} / \mathrm{g})$ of total fatty acids of adipose tissue from rats fed essential fatty acid-deficient diet

(Mean values with their standard errors)

\begin{tabular}{|c|c|c|c|c|c|c|c|c|c|c|c|}
\hline Fatty & acid... & $16: 0$ & & 16: & & $18: 0$ & & 18: & & $18: 2$ & \\
\hline$n$ & (weeks) & Mean & SE & Mean & SE & Mean & SE & Mean & $\mathrm{SE}$ & Mean & $\mathrm{SE}$ \\
\hline $\begin{array}{l}4 \\
4\end{array}$ & $\begin{array}{l}12 \\
16\end{array}$ & $\begin{array}{l}335 \\
263\end{array}$ & $\begin{array}{r}7 \\
12\end{array}$ & 103 & $\begin{array}{r}16 \\
4\end{array}$ & $\begin{array}{l}43 \\
34\end{array}$ & $\begin{array}{l}5 \\
6\end{array}$ & $\begin{array}{l}459 \\
383\end{array}$ & $\begin{array}{l}19 \\
11\end{array}$ & $\begin{array}{l}19 \\
18\end{array}$ & 3 \\
\hline
\end{tabular}

Fatty acid analysis of adipose tissue lipids was carried out at 2 weeks and 16 weeks. The results are shown in Table 5 and reveal very low levels of linoleate in adipose tissue at these times.

\section{DISCUSSION}

Although the predominant saponifiable lipid in the lymphocyte is membrane phospholipid, there could have been some contribution from the triglyceride fraction in our analyses of total fatty acids of lymphocytes. However, the evidence is that triglyceride fatty acids are available for phospholipid synthesis when required (Borowitz \& Blum, 1976; Tsai \& Geyer, 1978). Thus, even if the triglycerides did contain small amounts of arachidonate, the results 
we have provided on total lipid fatty acid patterns gave a true picture of the total available arachidonate.

Although the fatty acid changes shown between 2 and 12 weeks are relatively minor, they must initiate mechanisms which, on the one hand, slow the growth rate, and on the other are capable of affecting the immune response; graft rejection experiments have not been carried out on rats fed essential fatty acid-deficient diets, but acceleration of skin graft rejection in mice occurs after only $4-5$ weeks on the diet (Mertin \& Hunt, 1976). Some evidence is emerging of hormonal changes in essential fatty acid deficiency which may be implicated in the changes in growth rate (Nugara \& Edwards, 1970; Engster et al. 1979). Whether the mechanism which slows the growth rate and that which affects the immune response are the same, or whether separate pathways are involved, and how they arise from the early essential fatty acid deficiency are points for further investigation. In any study on the effect of essential fatty acid deficiency on the immune response, it would be useful to monitor the effect of the dietary treatment on the fatty acid patterns of the cells of the immune system.

Esterified membrane fatty acids appear to fulfil at least two functions. One is concerned with the maintenance of the physical properties of the membrane lipid bilayer (for reviews see Lenaz, 1979; Chapman et al. 1979). Another function is to provide precursors for metabolically important reactions such as the formation of arachidonic acid metabolites (Parker et al. I979). Regulation of the levels of individual fatty acids appropriate to these functions appears to be mediated in part by the inverse relationship between linoleate and oleate which has been revealed by this and other studies (Farquhar \& Ahrens, 1963; Ferguson et al. 1975; Awad \& Spector, 1976; Rintoul et al. 1978).

When linoleate levels are adjusted in response to dietary linoleate changes this inverse relationship between oleate and linoleate appears to permit the total sum of unsaturated fatty acids to remain relatively constant, without the need for changes in the arachidonate level, which may be important for the formation of arachidonate metabolites.

The authors wish to thank the Multiple Sclerosis Society and the Wellcome Trust for financial support.

\section{REFERENCES}

Awad, A. B. \& Spector, A. A. (1976). Biochim. biophys. Acta 426, 723.

Borowitz, M. J. \& Blum, J. J. (1976). Biochim. biophys. Acta 424, 114.

Bøyum, A. (1968). Scand. J. clin. Lab. Invest. 21, 3I, suppl. 97.

Chapman, D., Gomez-Fernandez, J. C. \& Goni, F. M. (1979). FEBS Lett. 98, 21 I.

Clausen, J. \& Møller, J. (1967). Acta neurol. scand. 43, 375.

Engster, H. M., Carew, L. B. Jr., Harvey, S. \& Scanes, C. G. (1979). J. Nutr. 109, 330.

Farquhar, J. W. \& Ahrens, E. H. Jr. (1963). J. clin. Invest. 42, 675.

Ferguson, K. A., Glaser, M., Bayer, W. H., Vagelos, P. R. (1975). Biochemistry, Easton 14, 146.

Folch, J., Lees, M. \& Sloane-Stanley, G. H. (1956). J. biol. Chem. 226, 497.

Guanieri, M. \& Johnson, R. M. (1970). Adv. Lipid Res. 8, 115.

Lenaz, G. (1979). The Role of Lipids in Membranes. Subcellular Biochemistry, vol. 6, ch. 5. [D. B. Roodyn, editor]. New York: Plenum Press.

Medawar, P. B., Hunt, R., Meade, C. J. \& Mertin, J. (1975). Proc. Nutr. Soc. 35, 147A.

Mertin, J. \& Hughes, D. (1975). Int. Archs Allergy appl. Immun. 48, 203.

Mertin, J. \& Hunt, R. (1976). Proc. nat. Acad. Sci. U.S.A. 73, 928.

Mertin, J. \& Stackpoole, A. (1979). Clin. exp. Immun. 36, 449.

Nugara, D. \& Edwards, H. M. Jr. (1970). J. Nutr. roo, 539.

Offner, H. \& Clausen, J. (1975). Lancet ii, 1204.

Parker, C. W., Stenson, W. F., Huber, M. G. \& Kelly, J. P. (1979). J. Immun. r2z, 1572.

Rintoul, D. A., Sklar, L. A. \& Simoni, R. D. (1978). J. biol. Chem. 253, 7447.

Santiago-Delpin, E. A. \& Szepsenwol, J. (1977). J. natn. Cancer Inst. 59, 459.

Selivonchick, D. P. \& Johnston, V. P. (1975). J, Nutr. 105, 288.

Tsai, P. \& Geyer, R. P. (1978). J. biol. Chem. 253, 5087.

Tsang, W. M., Weyman, C. \& Smith, A. D. (1977). Biochem. Soc. Trans. 5, 153.

Weyman, C., Morgan, S., Belin, J. \& Smith, A. D. (1977). Biochim. biophys. Acta 496, 155.

Yu, B. P., Kummerow, F. A. \& Nishida, T. (1966). J. Nutr. 89, 435. 